\title{
SIGNIFIKANSI KOREKSI NEWTON UNTUK MEMASUKKAN PENGARUH LINGKUNGAN PADA PERCOBAAN TARAKALOR MEKANIK
}

\author{
Nani Yuningsih ${ }^{\text {a) }}$, Kunlestiowati H. ${ }^{\text {b) }}$, Sardjito ${ }^{\text {c) }}$ \\ Politeknik Negeri Bandung, Jl.Gegerkalong Hilir, Ds. Ciwaruga, Kotak Pos 1234, Bandung 40012 \\ Email:a)nani.yuningsih@polban.ac.id, ${ }^{b}$ kunpolban@yahoo.co.id, ${ }^{c}$ sardjito@polban.ac.id
}

\begin{abstract}
Abstrak
Tujuan percobaan tarakalor mekanik adalah untuk membuktikan hukum kekekalan energi pada proses perubahan energi mekanik menjadi energi panas. Kalorimeter yang digunakan pada penelitian ini adalah kalorimeter tembaga pejal, tembaga berongga, dan aluminium pejal. Kalorimeter dililit dengan tali yang digantungi beban dan diputar selama 120 detik sehingga timbul gesekan antara tali dengan kalorimeter. Panas yang timbul akibat gesekan diserap oleh kalorimeter. Setelah diputar selama 120 detik, putaran dihentikan dan diukur panasnya selama 240 detik. Untuk mendapatkan hasil yang optimum, perlu memasukkan koreksi Newton laju pendinginan pada saat menghitung energi panas. Metoda yang digunakan dalam penelitian ini adalah analisis deskriptif dari data primer yang diperoleh dari percobaan di laboratorium dan pengolahan data berbantuan komputer. Pengaruh suhu lingkungan dalam konsep perubahan energi mekanik menjadi energi panas sangat kuat. Hal ini dibuktikan dengan perbandingan energi panas terhadap energi mekanik dengan memperhitungkan pengaruh suhu lingkungan lebih besar dari yang tanpa memperhitungkan pengaruh suhu lingkungan. Energi mekanik yang berubah menjadi energi panas masing-masing untuk kalorimeter tembaga berongga, tembaga pejal, dan aluminium pejal berturut-turut sebesar $80 \%, 89 \%$, dan $84 \%$ tanpa koreksi Newton dan $92 \%, 95 \%$, dan $94 \%$ dengan koreksi Newton. Hal ini membuktikan bahwa terdapat pengaruh signifikan penggunaan koreksi Newton dalam percobaan tarakalor mekanik.
\end{abstract}

Kata-kata kunci: Tarakalor mekanik, kalorimeter, koreksi Newton, laju pendinginan

\begin{abstract}
The aim of the mechanical heat experiment is to prove the conservation law of energy in the process of changing mechanical energy into heat energy. The calorimeter used in this study are solid copper calorimeter, empty copper calorimeter, and solid aluminium calorimeter. The calorimeter is wrapped around a load-hung rope and rotated for 120 seconds to create friction between the rope and the calorimeter. The heat arising from the friction is absorbed by the calorimeter. After rotating for 120 seconds, the rotation is stopped and the heat is measured for 240 seconds. To obtain optimum results, it is necessary to enter Newton's correction of the cooling rate when calculating the heat energy. The method used in this study is descriptive analysis from primary data taken in the laboratory and computer-assisted data processing. The influence of environmental temperature in the concept of changing the form of mechanical energy into heat energy is very strong. This is proved by the ratio of heat energy to mechanical energy by considering the influence of the environment temperature more than that without considering the influence of environment temperature. Mechanical energy that changes into heat for each empty copper calorimeter, solid copper calorimeter, and solid aluminium calorimeter are $80 \%, 89 \%$, and $84 \%$ respectively without Newton correction and $90 \%, 94 \%$, and $90 \%$ with Newton
\end{abstract}


correction. This proves that there is a significant influence on the use of Newton's correction in the mechanical heat experiment.

Keywords: mechanical heat, calorimeter, Newton correction, cooling rate.

\section{PENDAHULUAN}

Salah satu bahasan konsep fisika adalah konversi energi, pada dasarnya energi dapat berubah bentuk, contohnya energi mekanik dapat berubah bentuk menjadi energi panas, prinsip ini dikenal dengan istilah Tara kalor mekanik, yaitu kesetaraan energi mekanik dengan energi panas. Kesetaraan ini pada dasarnya menunjukkan jumlah energi panas yang dihasilkan sama dengan jumlah energi mekanik. Hukum kekekalan energi menyatakan bahwa energi tidak dapat dimusnahkan dan diciptakan melainkan hanya dapat diubah dari suatu bentuk energi ke bentuk energi yang lain. Untuk memahami konsep perubahan energi secara utuh, maka perlu dilakukan pengujian percobaan, dalam hal ini dilakukan pengujian percobaan tarakalor mekanik dengan memperhatikan faktor-faktor yang berpengaruh terhadap hasil. Jumlah putaran dan kecepatan sudut putar tuas merupakan besaran yang berpengaruh terhadap besar energi mekanik yang dihasilkan [1]. Untuk membuktikan kekekalan energi yang optimum, selain faktor kecepatan sudut putar usaha mekanik yang dilakukan, perlu memasukkan koreksi Newton laju pendinginan pada saat menghitung energi panas/kalor. Koreksi Newton adalah suatu cara untuk melakukan koreksi pengaruh suhu lingkungan saat proses perubahan energi dari satu bentuk energi ke bentuk energi yang lain [1]. Pengukuran panas antara kalorimeter dengan sekelilingnya selama percobaan berlangsung dapat pula menyebabkan penyimpangan hasil pengamatan. Bila temperatur kalorimeter tidak terlalu berbeda dengan temperatur sekelilingnya, maka dalam mengukur energi panas perlu memperhitungkan suhu lingkungan. Untuk melihat besar pengaruh suhu lingkungan terhadap hasil pengamatan perlu dilakukan koreksi terhadap panas yang dihasilkan dengan menggunakan koreksi Newton. Koreksi dilakukan terhadap suhu yang diukur saat proses pendinginan. Jika pada saat proses pendinginan diperoleh besar suhu yang diserap oleh lingkungan, maka besar suhu yang diserap oleh lingkungan juga berlaku pada proses pemanasan (perubahan usaha mekanik menjadi panas). Penelitian ini bertujuan untuk mendapatkan seberapa besar pengaruh suhu lingkungan terhadap perubahan energi yang terjadi dengan memasukkan koreksi Newton laju pendinginan.

Percobaan Tara Kalor Mekanik dapat membuktikan hukum kekekalan energi pada proses perubahan usaha mekanik menjadi energi panas. Perangkat alat yang digunakan dapat dilihat pada GAMBAR 1 .

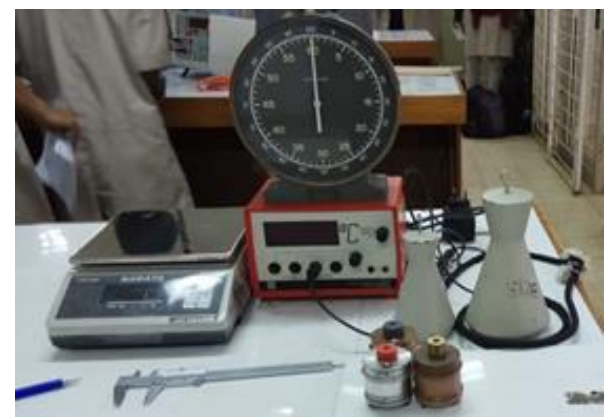

GAMBAR 1. Perangkat Alat Percobaan Tara Kalor Mekanik

Bejana kalorimeter yang dililit tali berbeban $\mathrm{Mg}$, jika diputar sebanyak $\mathrm{N}$ putaran tanpa mengakibatkan beban naik, akan menyerap usaha mekanik sebesar [1]:

$$
W=M g N \pi d
$$

Dimana:

$$
\begin{aligned}
& \mathrm{d}=\text { diameter bejana kalorimeter } \\
& \mathrm{M}=\text { massa beban yang dililit pada tali }
\end{aligned}
$$




$$
\begin{aligned}
& \mathrm{g}=\text { percepatan gravitasi } \\
& \mathrm{N}=\text { banyaknya putaran }
\end{aligned}
$$

Usaha tersebut diubah menjadi kalor $(\mathrm{Q})$ yang digunakan untuk mengubah suhu bejana serta isinya $(\Delta \mathrm{T})$, sehingga memenuhi persamaan [3]:

$$
\begin{aligned}
& W=Q \\
& Q=C . \Delta T
\end{aligned}
$$

dengan $\mathrm{C}=$ kapasitas panas kalorimeter.

Dalam membuktikan hukum kekekalan energi, pada proses perubahan usaha mekanik menjadi kalor, ada pengaruh temperatur ruangan, yang memenuhi perumusan hukum Newton laju pendinginan [4].

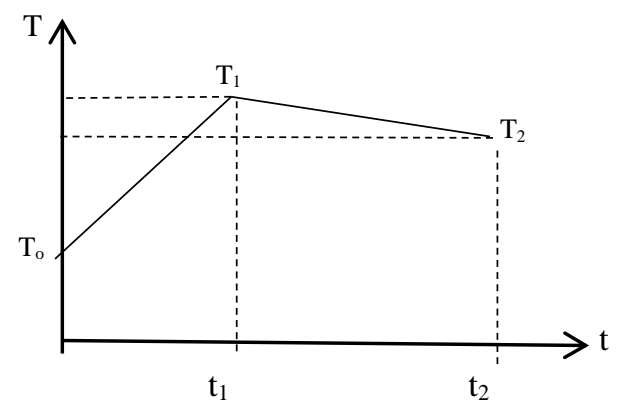

GAMBAR 2. Grafik hubungan suhu (T) terhadap waktu (t) [1]

GAMBAR 2 memperlihatkan hubungan antara perubahan suhu dan waktu ketika proses pemanasan dan pendinginan, dengan asumsi bahwa laju pendinginan bersifat linier.

Persamaan koreksi Newton laju pendinginan dapat dituliskan sebagai berikut $[1,5]$ :

$$
\frac{T_{1}-T_{2}}{\Delta t_{2}}=k\left(T_{c}-T_{r}\right)
$$

dan

$$
\frac{\Delta T_{1}}{\Delta t_{1}}=k\left(\frac{T_{0}-T_{1}}{2}-T_{r}\right)
$$

Dengan:

$\mathrm{T}_{\mathrm{o}}=$ suhu awal

$\mathrm{T}_{1}=$ suhu akhir proses pemanasan

$\mathrm{T}_{2}=$ suhu akhir proses pendinginan

$\mathrm{T}_{\mathrm{r}}=$ suhu ruang

$\mathrm{T}_{\mathrm{c}}=$ suhu rata-rata kalorimeter saat laju pendinginan,

$\mathrm{k}=$ koefisien koreksi Newton

Perubahan panas pada persamaan (3) harus memenuhi $\Delta \mathrm{T}=\mathrm{T}_{\max }-\mathrm{T}_{\mathrm{o}}$, dengan $\mathrm{T}_{\max }=\mathrm{T}_{1}+\Delta \mathrm{T}_{1}$.

\section{METODE PENELITIAN}

Metode yang digunakan dalam penelitian ini adalah analisis deskriptif dari eksperimen di laboratorium dan pengolahan data berbantuan komputer. Prosedur penelitian terdiri dari beberapa langkah, yaitu menyiapkan alat percobaan tara kalor mekanik berkaitan dengan pengambilan data 
yang diperlukan dalam kegiatan penelitian, melakukan pengujian dengan mengambil data percobaan tara kalor mekanik, mengolah data dengan menghitung energi panas yang dihasilkan tanpa dan dengan koreksi Newton laju pendinginan.

Dalam penelitian ini digunakan tiga jenis kalorimeter yaitu kalorimeter tembaga berongga yang diisi dengan air, kalorimeter tembaga pejal, dan kalorimeter alumunium pejal. Kalorimeter dililit dengan tali yang digantungi beban bermasa $\mathrm{m}$ dan diputar selama 120 detik (waktu pemanasan) sehingga timbul gesekan antara tali dengan kalorimeter. Setelah diputar selama 120 detik, putaran dihentikan dan diukur panasnya selama 240 detik (waktu pendinginan). Perubahan temperatur dicatat setiap 15 detik selama pemanasan dan pendinginan.

\section{HASIL DAN PEMBAHASAN}

Pada percobaan ini yang menjadi pengamatan adalah banyaknya putaran dan perubahan temperatur setiap 15 detik selama pemanasan 120 detik, dan perubahan temperatur selama pendinginan 240 detik. Pengambilan data dilakukan 5 kali untuk masing-masing kalorimeter. Untuk mendapatkan besar usaha mekanik yang dilakukan digunakan persamaan (1) dan untuk mendapatkan panas yang dihasilkan digunakan persamaan (3). Untuk energi panas, dalam menentukan perbedaan temperatur $(\Delta \mathrm{T})$, dihitung dengan dua cara, yaitu tanpa memasukkan pengaruh suhu lingkungan dan dengan memasukkan pengaruh suhu lingkungan. Pengaruh suhu lingkungan dihitung dengan koreksi Newton menggunakan persamaan (4) dan persamaan (5).

Spesifikasi kalorimeter, massa beban yang digunakan, waktu pendinginan, dan waktu pemanasan dapat dilihat pada TABEL 1.

\begin{tabular}{lllllll}
\multicolumn{7}{c}{ TABEL 1. Spesifikasi kalorimeter dan waktu yang digunakan } \\
\hline No. & $\begin{array}{l}\text { Jenis } \\
\text { Kalorimeter }\end{array}$ & $\begin{array}{l}\text { Diameter, d } \\
(\mathbf{m m})\end{array}$ & $\begin{array}{l}\text { Kapasitas panas } \\
\text { kalorimeter, } \\
(\mathbf{J} / \mathbf{K})\end{array}$ & $\begin{array}{l}\text { Waktu } \\
\text { pemanasan } \\
\text { (detik) }\end{array}$ & $\begin{array}{l}\text { Waktu } \\
\text { Pendinginan } \\
\text { (detik) }\end{array}$ & $\begin{array}{l}\text { Massa } \\
\text { Beban } \\
(\mathbf{k g})\end{array}$ \\
\hline 1 & $\begin{array}{l}\text { Tembaga } \\
\text { berongga }\end{array}$ & 46.6 & 40 & 120 & 240 & 2 \\
2 & $\begin{array}{l}\text { Tembaga pejal } \\
3\end{array}$ & 47 & 264 & 120 & 240 & 5 \\
\hline
\end{tabular}

Untuk kalorimeter tembaga berongga, diisi dengan air, sehingga kapasitas panasnya $C=C_{k}+C_{a i r}$, dimana $C_{k}=$ kapasitas panas kalorimeter dan $C_{a i r}=$ kapasitas panas air , dengan $C_{a i r}=4,2(\mathrm{~m}) \mathrm{J} / \mathrm{g} . \mathrm{K}$ $(\mathrm{m}=$ massa air dalam satuan gram). Kemudian dihitung perbandingkan energi panas terhadap energi mekanik.

\section{Kalorimeter Tembaga Berongga}

Hasil perhitungan kalorimeter tembaga berongga, yang terdiri dari perbandingan energi panas dengan memasukkan pengaruh suhu lingkungan (Q') terhadap energi mekanik(W) dan perbandingan energi panas tanpa memasukkan pengaruh suhu lingkungan $(Q)$ serta kesalahan relatif rata-rata (KSR) dapat dilihat pada TABEL 2. GAMBAR 3 menunjukkan grafik hubungan antara Q terhadap W dan Q' terhadap W.

TABEL 2. Perbandingan energi panas dan energi mekanik dengan dan tanpa koreksi Newton kalorimeter tembaga

\begin{tabular}{ccccc}
\hline $\begin{array}{c}\text { Pengujian } \\
\text { ke- }\end{array}$ & $\begin{array}{c}\text { Jumlah Putaran } \\
(\mathbf{N})\end{array}$ & $\begin{array}{c}\text { Q/W } \\
\text { (tanpa Koreksi } \\
\text { Newton) }\end{array}$ & $\begin{array}{c}\text { Q'/W } \\
\text { (dengan Koreksi } \\
\text { Newton) }\end{array}$ & Kesalahan relatif \\
\hline 1 & 227 & 0,8575 & 0,8828 & 0,0286 \\
2 & 227 & 0,8329 & 0,9527 & 0,1257 \\
3 & 242 & 0,8416 & 0,9731 & 0,1351 \\
4 & 250 & 0,8491 & 0,8939 & 0,0502 \\
5 & 292 & 0,6737 & 0,7534 & 0,1057 \\
\hline
\end{tabular}




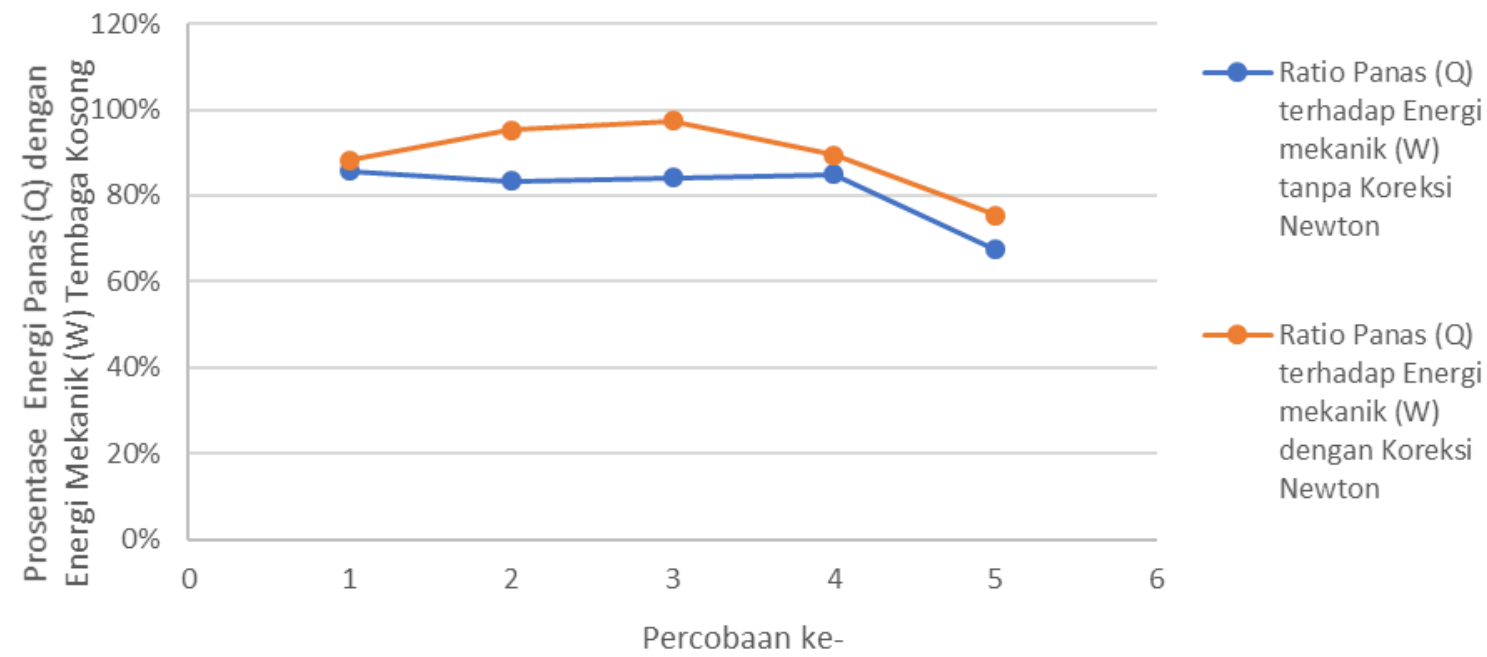

GAMBAR 3. Grafik perbandingan energi panas (Q) terhadap energi mekanik (W) kalorimeter tembaga berongga

Dari TABEL 2 dan GAMBAR 3 dapat disimpulkan bahwa perbandingan energi panas yang dihasilkan oleh usaha mekanik yang dilakukan terhadap kalorimeter tembaga berongga dengan melakukan koreksi Newton lebih besar daripada perbandingan energi panas dan usaha mekanik tanpa melakukan koreksi Newton. Hal ini menunjukkan bahwa panas yang timbul sebenarnya lebih besar dari yang terukur oleh termometer, namun karena suhu lingkungan lebih rendah maka sebagian panas yang timbul diserap oleh lingkungan selama proses pemanasan dan pendinginan.

\section{Kalorimeter Tembaga Pejal}

Sama halnya dengan kalorimeter tembaga berongga, dilakukan cara yang sama untuk kalorimeter tembaga pejal dengan hasil seperti TABEL 3 dan GAMBAR 4.

\begin{tabular}{ccccc}
\multicolumn{4}{c}{ TABEL 3. Perbandingan energi panas dan energi mekanik dengan dan tanpa koreksi newton kalorimeter tembaga pejal } \\
\hline $\begin{array}{c}\text { Pengujian } \\
\text { ke- }\end{array}$ & $\begin{array}{c}\text { Jumlah Putaran } \\
\text { (N) }\end{array}$ & $\begin{array}{c}\text { Q/W } \\
\text { (tanpa Koreksi } \\
\text { Newton) }\end{array}$ & $\begin{array}{c}\text { Q'/W } \\
\text { (dengan Koreksi } \\
\text { Newton) }\end{array}$ & Kesalahan relatif \\
\hline 1 & 212 & 0,8764 & 0,9279 & \\
2 & 223 & 0,8740 & 0,9177 & 0,0556 \\
3 & 223 & 0,8649 & 0,9035 & 0,0476 \\
4 & 288 & 0,9360 & 0,9765 & 0,0427 \\
5 & 288 & 0,9234 & 0,9765 & 0,0415 \\
\end{tabular}




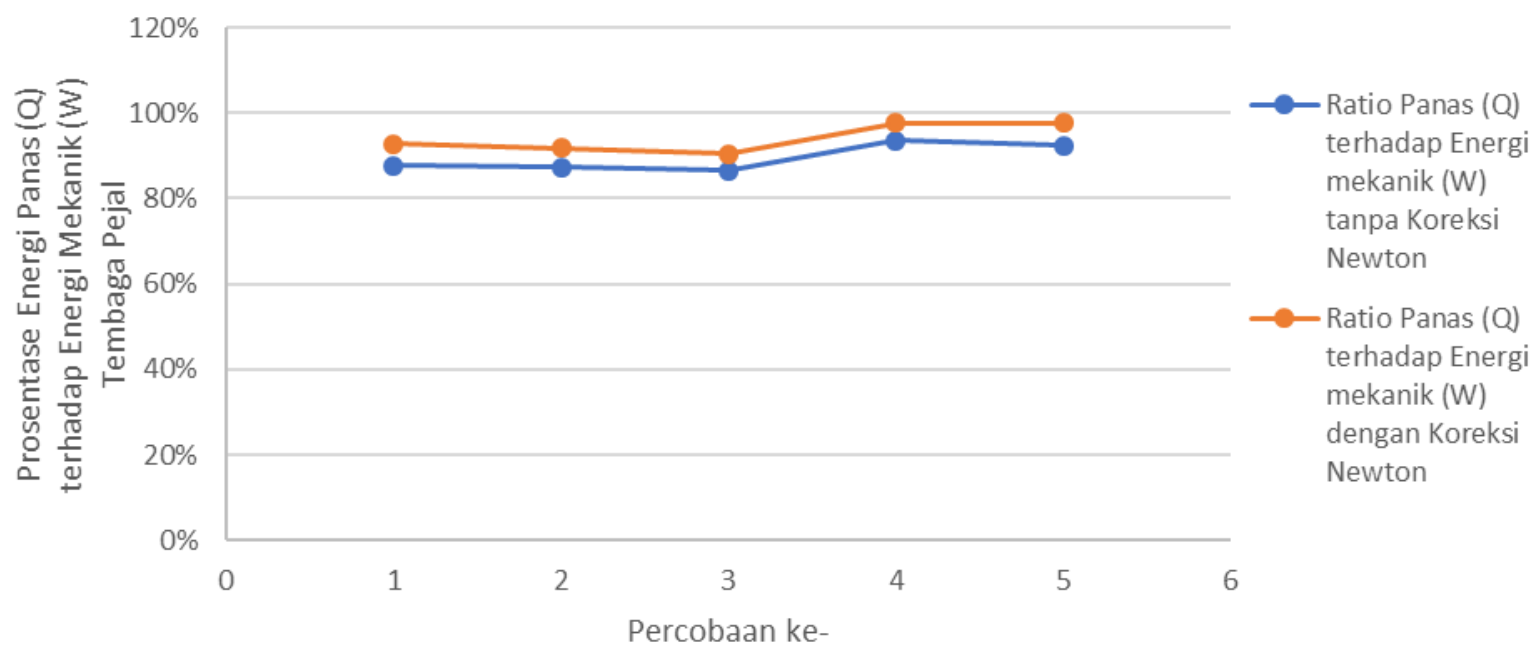

GAMBAR 4. Grafik perbandingan energi panas (Q) terhadap energi mekanik (W) kalorimeter tembaga pejal

Hasil perhitungan kalorimeter alumunium pejal seperti TABEL 4 dan grafik hubungan antara energi panas terhadap energi mekanik terlihat pada GAMBAR 5.

TABEL 4. Perbandingan energi panas dan energi mekanik dengan dan tanpa koreksi newton kalorimeter aluminium pejal

\begin{tabular}{ccccc}
\hline $\begin{array}{c}\text { Pengujian } \\
\text { ke- }\end{array}$ & $\begin{array}{c}\text { Jumlah Putaran } \\
(\mathbf{N})\end{array}$ & $\begin{array}{c}\text { Q/W } \\
\text { (tanpa Koreksi } \\
\text { Newton) }\end{array}$ & $\begin{array}{c}\text { Q'/W } \\
\text { (dengan Koreksi } \\
\text { Newton) }\end{array}$ & Kesalahan relatif \\
\hline 1 & 212 & 0,914 & 0,968 & 0,056 \\
2 & 215 & 0,775 & 0,862 & 0,100 \\
3 & 221 & 0,897 & 0,969 & 0,073 \\
4 & 229 & 0,831 & 0,879 & 0,054 \\
5 & 238 & 0,789 & 0,850 & 0,072 \\
\hline
\end{tabular}

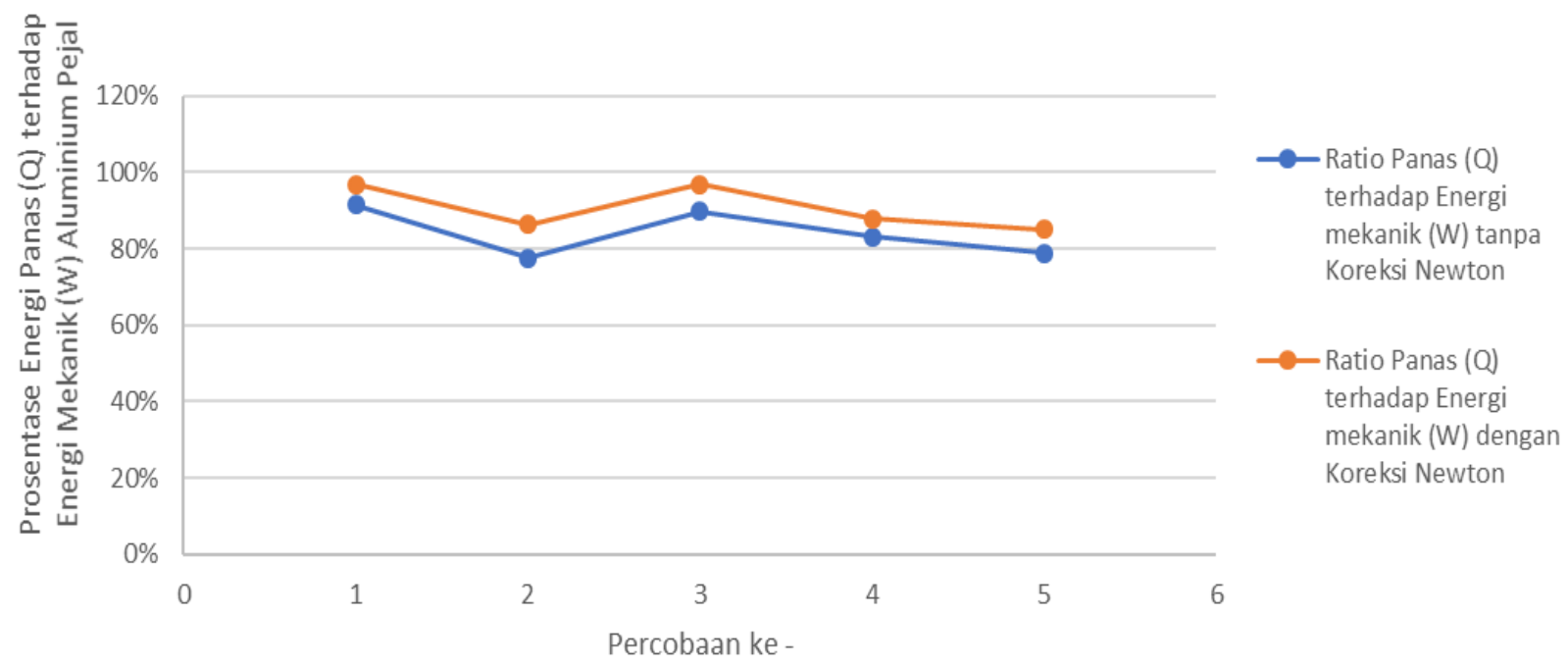

GAMBAR 5. Grafik perbandingan energi panas (Q) terhadap energi mekanik (W) kalorimeter aluminium pejal 
Dari ketiga kalorimeter yang diamati diperoleh bahwa energi mekanik yang diubah menjadi energi panas terbukti lebih mendekati hukum kekekalan energi jika energi panas yang dihasilkan dihitung dengan memasukkan pengaruh lingkungan yang dikoreksi dengan Koreksi Newton. Besar usaha mekanik yang berubah menjadi energi dalam bentuk lain setelah memasukkan pengaruh suhu lingkungan dan signifikansi koreksi Newton terhadap hasil pengamatan dapat dilihat pada TABEL 5.

TABEL 5. Perubahan Energi Mekanik menjadi Energi Panas

\begin{tabular}{|c|c|c|c|c|c|c|c|c|}
\hline \multirow[t]{2}{*}{$\begin{array}{c}\text { Jenis } \\
\text { Kalorimeter }\end{array}$} & \multirow{2}{*}{$\begin{array}{c}\text { Usaha } \\
\text { Mekanik } \\
\text {,W } \\
\text { (joule) }\end{array}$} & \multirow{2}{*}{$\begin{array}{c}\text { Energi } \\
\text { Panas } \\
\text { tanpa } \\
\text { koreksi } \\
\text { Newton, Q } \\
\text { (joule) }\end{array}$} & \multirow{2}{*}{$\begin{array}{c}\text { Energi } \\
\text { Panas } \\
\text { dengan } \\
\text { koreksi } \\
\text { Newton, Q' } \\
\text { (joule) }\end{array}$} & \multicolumn{2}{|c|}{$\begin{array}{c}\text { Energi yang } \\
\text { diubah dalam } \\
\text { bentuk lain } \\
\text { (tanpa Koreksi } \\
\text { Newton) }\end{array}$} & \multicolumn{2}{|c|}{$\begin{array}{c}\text { Energi yang } \\
\text { diubah dalam } \\
\text { bentuk lain } \\
\text { (dengan Koreksi } \\
\text { Newton) }\end{array}$} & \multirow{2}{*}{$\begin{array}{l}\text { Signifikansi } \\
\text { Koreksi } \\
\text { Newton } \\
\text { terhadap } \\
\text { hasil }\end{array}$} \\
\hline & & & & $\begin{array}{l}\text { Besar } \\
\text { Energi } \\
\text { (joule) }\end{array}$ & $\%$ & $\begin{array}{l}\text { Besar } \\
\text { Energi } \\
\text { (joule) }\end{array}$ & $\%$ & \\
\hline $\begin{array}{l}\text { Tembaga } \\
\text { Kosong }\end{array}$ & 698,534 & 561,792 & 617,206 & 136,742 & $20 \%$ & 81,328 & $12 \%$ & $92 \%$ \\
\hline $\begin{array}{l}\text { Tembaga } \\
\text { Pejal }\end{array}$ & 1803,946 & 1620,96 & 1703,13 & 182,986 & $10 \%$ & 100,816 & $6 \%$ & $95 \%$ \\
\hline $\begin{array}{l}\text { Aluminium } \\
\text { Pejal }\end{array}$ & 1614,296 & 1357,36 & 1460,628 & 256,936 & $16 \%$ & 153,668 & $10 \%$ & $94 \%$ \\
\hline
\end{tabular}

Berdasarkan hasil perhitungan perbandingan antara energi panas tanpa memperhitungkan suhu lingkungan (Q) dan energi panas dengan memperhitungkan suhu lingkungan (Q') terhadap energi mekanik(W), maka seluruh perhitungan hasilnya Q'/W lebih besar dari $\mathrm{Q} / \mathrm{W}$ dan penyimpangan rata-rata untuk setiap kalorimeter masing-masing kalorimeter tembaga berongga $8 \%$, kalorimeter tembaga pejal $5 \%$ dan kalorimeter Alumunium pejal $6 \%$.

Hasil tersebut membuktikan bahwa suhu lingkungan berpengaruh terhadap keberlakuan hukum kekekalan energi, sehingga untuk percobaan tarakalor mekanik dalam menghitung energi panas harus memperhitungkan pengaruh lingkungan.

\section{SIMPULAN}

Perbandingan energi panas (Q) terhadap energi mekanik (W) dengan memperhitungkan suhu lingkungan (Q'/W) lebih besar dari pada tanpa memperhitungkan suhu lingkungan $(\mathrm{Q} / \mathrm{W})$. Hal ini menunjukkan pengaruh suhu lingkungan dalam konsep perubahan bentuk energi mekanik menjadi energi panas sangat kuat. Signifikansi penggunaan koreksi Newton terhadap proses perubahan energi mekanik menjadi energi panas kalorimeter tembaga kosong, kalorimeter tembaga pejal, dan kalorimeter aluminium pejal berturut-turut sebesar $92 \%, 95 \%$, dan $94 \%$.

\section{UCAPAN TERIMAKASIH}

Terimakasih kepada Politeknik Negeri Bandung melalui Unit Penelitian dan Pengabdian kepada Masyarakat (UPPM) Politeknik Negeri Bandung yang telah mendanai penelitian Mandiri tahun 2018 ini dan kepada rekan-rekan pengajar Fisika Terapan Polban yang telah turut berkonstribusi dalam penelitian ini. 


\section{REFERENSI}

[1] N. Yuningsih, "Optimasi Besaran Fisis Yang Mempengaruhi Proses Konversi Energi (Studi Kasus Percobaan Tara Kalor Mekanik Dan Hukum Joule), Prosiding Seminar Nasional Fisika (e-journal) SNF 2018, Vol VII, PA 77-84, Oktober 2018.

[2] H. Kunlestiowati, "Analisis penyimpangan konversi energi listrik menjadi kalor pada perangkat eksperimen Hukum Joule", JRKPF UAD, Vol. 5, No.1, pp 34-39, 2018.

[3] Halliday, Resnick, Walker, "Temperature, Heat, and the First Law of Thermodynamics" in Fundamental of Physics, 6th ed. New Delhi, India: Wiley, 2006, pp 425-448.

[4] Emma Carlson Berne "Heat Energy". The Rosen Publishing Group. p. 18. ISBN 978-1-4488-9886-2, p. 18, Januari 2013.

[5] Panduan Praktikum Fisika, Politeknik Negeri Bandung, Bandung, 2012, pp 34-39. 